\title{
A geographical information systems-based approach to health facilities and urban traffic system in Belgrade, Serbia
}

\author{
Aleksandar Valjarević, ${ }^{1,2}$ Dragana Valjarević, ${ }^{3}$ Zorica Stanojević-Ristić, ${ }^{4}$ Tatjana Djekić, ${ }^{5}$ \\ Nebojša Živić
}

${ }^{1}$ Department for Management of Science and Technology Development, Ton Duc Thang University, Ho Chi

Minh City, Vietnam; ${ }^{2}$ Faculty of Environment and Labour Safety, Ton Duc Thang University, Ho Chi Minh City, Vietnam; ${ }^{3}$ Department of Mathematics, Faculty of Natural Science and Mathematics, University of

Kosovska Mitrovica, Kosovska Mitrovica, Serbia; ${ }^{4}$ Department of Pharmacology and Toxicology, Institute of Pharmacology, Faculty of Medicine, University of Kosovska Mitrovica, Kosovska Mitrovica, Serbia;

${ }^{5}$ Department of Geography, Faculty of Science and Mathematics, University of Niš, Niš, Serbia;

${ }^{6}$ Department of Biology, Faculty of Natural Science and Mathematics, University of Kosovska Mitrovica,

Kosovska Mitrovica, Serbia

\begin{abstract}
We studied the geospatial distribution of health facilities in Belgrade, the capital of the Republic of Serbia, in relation to the public transport system. Analyses in this research were based on advanced geographical information systems using numerical methods. We calculated accessibility to health centres as based on public transport properties accounting for the movement of citizens, as well as patients, through the city. Based on results, the city of Belgrade has a moderate connectivity. Public health centres and a group of other health centres in the central-east part of the city
\end{abstract}

Correspondence: Aleksandar Valjarević, Department for Management of Science and Technology Development, Ton Duc Thang University, Ho Chi Minh City, Vietnam.

Tel.: +381668006450 .

E-mail: aleksandar.valjarevic@tdtu.edu.vn

Key words: GIS analysis; Accessibility; Health centres; Public transport; Gravity model; Belgrade; Serbia.

Contributions: the authors contributed equally.

Conflict of interest: the authors declare no potential conflict of interest.

Funding: none.

See online Appendix for additional materials.

Received for publication: 29 July 2018.

Revision received: 11 October 2018.

Accepted for publication: 11 October 2018.

(C) Copyright A. Valjarević et al., 2018

Licensee PAGEPress, Italy

Geospatial Health 2018; 13:729

doi:10.4081/gh.2018.729

This article is distributed under the terms of the Creative Commons Attribution Noncommercial License (CC BY-NC 4.0) which permits any noncommercial use, distribution, and reproduction in any medium, provided the original author(s) and source are credited. have a better connectivity. Also, in this paper we estimated that the average time necessary to reach health facilities on foot is 100 minutes and by public transport vehicles such as buses, trams and trolleys is 42 minutes.

\section{Introduction}

Geospatial analysis is of considerable and increasing importance today. Geographical Information Systems (GIS) and Global Positioning Systems (GPS) can be applied for the analysis of various aspects of health care, e.g., needs, access or utilization as well as for planning, evaluating service locations and spatial decision for health care delivery (McLafferty, 2003; Bartie et al., 2006; Higgs, 2009). In South Africa (Hlabisa), community-based tuberculosis treatment program documents the increase in accessibility to treatment after the expansion of the service from health facilities and inclusion of community workers and volunteers (Wilkinson and Tanser, 1999). In other investigations researchers used GIS to study data for malaria distribution and its volume (Martin et al., 2002). In Thailand a spatial pattern detection has been used for understanding the geographical distribution of hypertension (Laohasiriwong et al., 2018). In Costa Rica, a study was conducted to relate the 2000 census population (demand) with an inventory of health facilities. The GIS platform was developed for this study to allow pinpointing communities to improve the accessibility to health care (Bixby, 2004).

GIS allows interactive information contained in maps, tables or graphs (Najafabadi, 2009). In some countries, especially in the UK, there is strong connection between health services and GIS applications (Bullen et al., 1996). Beside GIS analysis, other spatial methods can lead to a satisfying result, e.g., in analysing extreme meteorological data in correlation with epidemic problems (Ferreira, 2014). However, GIS modelling can be highly useful with respect to climatological modelling in comparison with some diseases (Mortarino et al., 2008). The concept of accessibility to certain points in space was successfully studied by De Jong et al. (1991), while Geertman and Bosveld (1990) describe an application in the town planning and Pouliou et al. (2014) have shown that GIS in combination with buffer analysis can give precise results in estimation of geospatial properties.

The health care system in Serbia is divided into primary, sec- 
ondary and tertiary sector. The primary medical care includes preventive and medical activities which include dentistry, epidemiology, emergency medical assistance, family medicine, gynaecology, home care medicine, paediatrics, school medicine, etc. In the territory of Belgrade there are 135 health facilities, 56 of them belonging to primary medical care, 50 to secondary and 29 to tertiary (Appendix). In Serbia, there are two types of health care, private and public, where the latter belongs to the local community as well as to the whole municipality. Hierarchically, health care facilities belong either to the municipalities, to the region or to the state. Private health facilities were first established in 1996 during the period of privatization in former Yugoslavia, and that state of affairs continues today in Serbia. After the year 2000, the private sector, including private health care facilities, attained a higher level. In the period 2000-2015, the participation of the private sector in health care increased to $45 \%$ of all care in Serbia. At present, the Serbian Ministry of Health is trying to equalize access and quality with regard to public and private health care. Although there are differences, many health centres operate by rules covering both health care systems. The territory of Serbia covers an area of $88407 \mathrm{~km}^{2}$. Serbia has the south-east position in the Balkan Peninsula (Valjarevic et al., 2015). Some health facilities in Belgrade are not accessible by the public transport lines, especially from the bus station. In this study we aimed to compare traffic mobility, geospatial dispersion of health centres and their potential availability by choosing a practical and valid method of delimiting health service areas of regional health service centres. We applied two methods to delimit health service areas: the proximal method and the gravity method (Xiong and Luo, 2017), where the geographical gravitational interaction defined as a force acting between two centres (with the masses represented by their population densities) divided by the distance (Anderson, 2012).

\section{Materials and Methods}

\section{Study area and population}

Belgrade is the capital and the largest urban centre in Serbia. It is divided into 17 municipalities (Barajevo, Grocka, Čukarica, Lazarevac, Mladenovac, Novi Beograd, Obrenovac, Palilula, Rakovica, Savski venac, Sopot, Stari grad, Surčin, Voždovac, Vračar, Zemun and Zvezdara) covering a total area of 3,327 $\mathrm{km}^{2}$ (Simić, 1974; Statistical Office of the Republic of Serbia, 2015). The development of rural settlements in the northern part of periurban space is currently changing the landscape (Matijević, 2005).

Depending of the geography, new developments and the public transport system, accessibility to health centres varies considerably between the different parts of the city. According to data made available from the Statistical Office of the Republic of Serbia, the current, total number of citizens in the city is about 1.6 million and the population rate increases by $0.46 \%$ per year.

\section{Data resources}

In this research we used two types of data. The first type was obtained by GPS receiver measurements using Garmin inReach Explorer+ (https://inreach.roadpost.ca/inreach-explorer-the-satellite-communicator-with-navigation/), while the second were official data that can be divided into maps, cadastral data (tax parcel information) and satellite recordings. The maps were analogue for- mat and came from the official site of Belgrade GSP, a public transport enterprise (http://www.gsp.rs/naslovna.aspx), while the cadastral data including information on the streets were found at the official page of the Republic Geodetic Authority (http://en.rgz.gov.rs/). From this web page we successfully downloaded streets in shape extension and Keyhole Markup Language. The satellite recordings data were downloaded from the official web page of the United States Geological Survey and from the official web page Earth Explorer - LANDSAT (http://earthexplorer.usgs.gov/). An exceptional view of digital elevations was also downloaded The Aster Global Dem website (https://asterweb.jpl. nasa.gov/gdem.asp). The downloaded data were imported into the GIS software and the territory of Belgrade was cropped for future manipulating.

\section{Geographical information systems support used}

Complex networks in combination with the dispersion of health centres are the subjects of interest for many fields of medicine, such as social medicine, urban-transport medicine, emergency medicine, etc. (Matthew et al., 2006; Srivastava et al., 2009). For the purpose of this research we used the open source Quantum Geographic Information System software (QGIS) (https://qgis.org/en/site/) and System for Automated Geoscientific Analyses (http://www.saga-gis.org/en/index.html). These software systems are particularly useful because they contain algorithms for autocorrelation and minimized potential error of geo-statistical estimations, as well as allowing the distribution of health centres and their properties to be studied in connection with the public transport system. In addition, some old topographic maps were georeferenced and digitized (Featherstone, 1994; Zhan and Noon, 1998; Valjarević et al., 2017). Coordinates of all 135 health facilities were imported into the GIS employing also ordinary Kriging and global Kriging methods, which includes gravity law interaction. Ordinary Kriging also includes autocorrelation and the statistical relationship between measured points. Thus, with this method, the weights can be based not only on the distance between the measured points and the prediction of location, but also on the overall spatial arrangement of the measured points minimizing the variance of the error of estimation (Wu and Chen, 2016; Valjarević et al., 2018a). In some other advanced GIS analyses we applied numerical and special interpolation techniques to get a precise grid (Valjarević et al., 2018b). Algorithms for creation of these maps were added into GIS adapting them to the gravity law and transport network problems (Figure 1). GIS and cadastral data make it possible to reconstruct streets and traffic properties (Bartie et al., 2006). Special methods, such as hexagonal and gravity power, provide a better estimate of the relationship between health facilities and their geospatial properties. The QGIS approach was successfully improved by adding algorithms allowing the calculations of gravity power and influence. Also, within the same software, we calculated the number and physical properties of hexagons using MMQGIS (http://michaelminn.com/linux/mmqgis/), a set of plugins for manipulating vector map layers in QGIS. In this way, this grid layer showed real properties of all health facilities in Belgrade.

\section{Spatial interaction patterns}

In this research we considered the concept of accessibility based on the modified gravity model and spatial analysis (Ogunyemi et al., 2014). Accessibility to the transport network can be described as reaching a destination at a low cost by spending a 
small amount of energy (Handy, 1997). The concept of accessibility incorporates not only the transport link between the origin and the destination and ability for travelling to the target, but also the characteristics of the destination and the objective of the trip. The time spent by potential patients for reaching their destination can be looked upon in two ways; the first for those travelling by public transport, and the second for those on foot. In order to calculate the time of walking, we created hexagonal maps for the whole study area. We included travel time to access point in the GIS analysis of traffic network and health facilities (De Jong and Ritsema, 1999). To find better locations of bus stop points, we used algorithm of proximity counting (De Jong et al., 1991). Proximity Count simply adds up all potential clients that live within a given distance range (travel time of 20 minutes on foot). This distance is varying depending on the properties of traffic network, public transport capacity, health centre capacity as well as location of the patients in state of recuperation. For that purpose, we divided the city of Belgrade into hexagons including streets and bus stops.

\section{Geospatial gravity model}

Adapted GIS applications are useful in the geo-space investigations (Joyce, 2009) and gravitational models in geography have long tradition (Niedercorn and Bechdolt, 1969; Rodrigue and Comtois, 2013). The advantages lie in the capacity of analyzing the transport system, as well determining the distribution of objects in geo-space (Higgs and Gould, 2001; Cromley and McLafferty, 2011). To evaluate the total properties of public transport resources we used multi-criterial analysis including the gravity adapted model, which can be implemented in the maps with a specific algorithm available in the GIS software. According to Anderson (2012). The geographical gravitational interaction may be defined as a force $(\mathrm{F})$ acting between two centres (A and B) with their masses (population densities) $\mathrm{m}_{\mathrm{A}}$ and $\mathrm{m}_{\mathrm{B}}$ divided by the distance $\mathrm{d}_{\mathrm{AB}}$ (Eq. 1):

$$
\mathrm{F}_{\mathrm{AB}}=\frac{\gamma \times \mathrm{m}_{\mathrm{A}} \times \mathrm{m}_{\mathrm{B}}}{\mathrm{d}_{\mathrm{AB}}}
$$

where $\gamma$ is gravitational constant. Hence, in gravity the negative impact of distance can be offset by the positive impact of mass represented by the population density as discussed by Howard et al. (1997) and Ports et al. (2006) (Eq. 2):

$$
\mathrm{I}_{\mathrm{AB}}=\mathrm{k} \frac{\mathrm{P}_{\mathrm{A}} \mathrm{P}_{\mathrm{B}}}{\mathrm{d}^{2}}
$$

where $I_{A B}$ is a form of spatial interaction and $P$ the population of each place. The factor $k$ must be determined separately from observed data for each context in which the model is applied (Eq. 3):

$$
\mathrm{I}_{\mathrm{AB}}=\sum_{i, j} \mathrm{k} \frac{\mathrm{V}_{\mathrm{i}} \mathrm{W}_{\mathrm{j}}}{\mathrm{c}_{\mathrm{ij}}^{\mathrm{b}}}
$$

where $V_{i}$ is a measure of the capability of the origin to generate a spatial interaction, $W_{j}$ a measure of the capability of the destination $j$ to attract the spatial interaction and $c_{i j}$ a generalised power of interaction, which serves as an inverse measure of accessibility.
The constant $\mathrm{b}$, which can vary according to the context, must be estimated on the basis of the observed data. The constant $k$ in the gravity model is actually not constant at all. The best way to define $k$ is to conceive it as an empirical parameter that is used to provide the best possible prediction of a particular type of spatial interaction in a particular spatiotemporal context. Usually, an iterative calibration procedure is followed in which the travel time from the dissemination belt $i$ to the health facility location $j$ is computed with different distance parameters until the predicted average trip length fits satisfactorily the result of the survey. Only then, can we have the travel time $C_{i j}$. The model with the calibrated distance parameter $k$ can then be used to predict the future patterns for alternative proposals with new bus stops at different locations. In this research, we successfully adapted some equations to a specific code in the Python program language (https://www.python.org/) and implemented them in QGIS. In the spatial tool AequilibraE within the QGIS we added the specific gravity model, which is very similar to Huff gravity model (Wei, 2004).

\section{Results}

After detailed GIS analysis we found the nearest access points of health facilities with regards to traffic public resources (Appendix). Multi-criteria GIS analysis gave the results of connectivity with decision criterium algorithm, and we also estimated connectivity in three classes. The first is within the range of 80$100 \%$ and presents excellent connectivity. The second is within 20$80 \%$ and presents moderate connectivity, while the third represents connectivity between $0 \%$ to $20 \%$ presents very low connectivity. Only in the first (20-80\% connectivity) has satisfying connectivity between public transport and health centres. As shown in Figure 2, street network analyses were applied to evaluate the density of population in the study area with accessibility to public transport

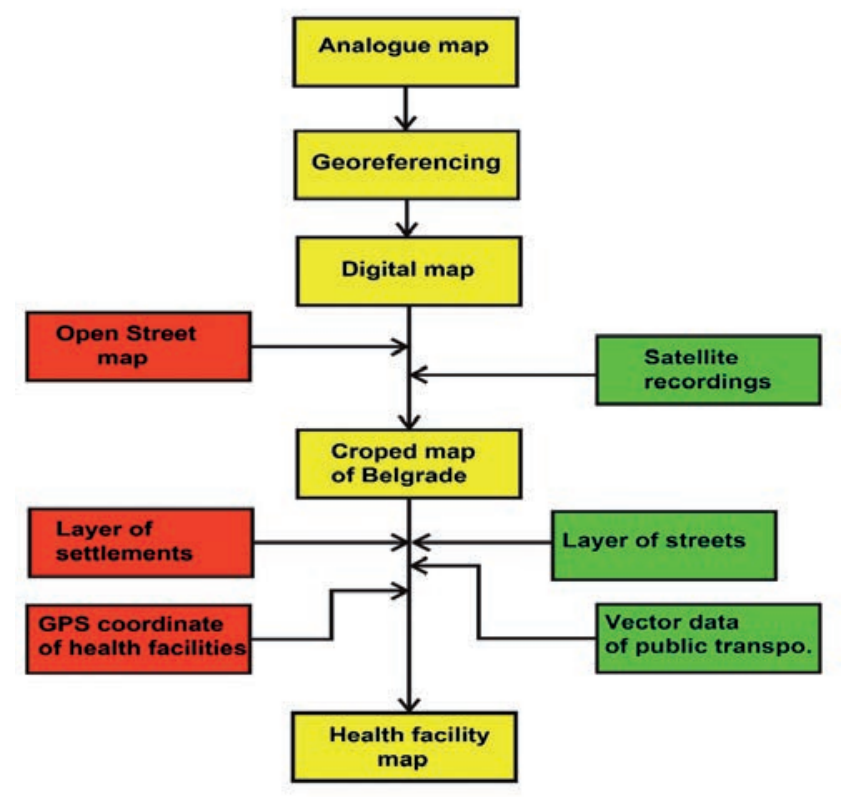

Figure 1. The procedures of algorithms in this research. 
network. When completed, GIS analysis gave the following results. The central-east group of health centres has a stronger connectivity than the southern and northern parts. Furthermore, health centres with government jurisdiction have an almost $20 \%$ better connectivity. One reason that could be the fact is that in the former Yugoslavia, when Belgrade was built, all national health centres were connected with public transport lines, especially by tram and trolley. After the year 2000, when private health centres first appeared, these new centres could be reached only by bus lines. In this research, we discovered that only private health centres in New Belgrade have good connectivity. The reason for that could be the fact that in this area there are three bridges connecting it to the centre. About $70 \%$ of health facilities in the western part of Belgrade have better connectivity than those in the North, and especially better than those in the southern part of Belgrade. The results, after total GIS analysis for 135 health centres, show that $25 \%$ of the health facilities have excellent connectivity, $40 \%$ moderate and $35 \%$ a rather low access. When the territory of Belgrade was tessellated into 6,400 equally sized $1.42 \mathrm{~km}^{2}$ hexagons we found the population in Belgrade highly dispersed (Figure 3) with an average of 250 potential citizens as well as patients concentrated per hexagon.

The densest area lies in the central-north part of the city followed by the central-west, central-east and central-south, in that order. As the densest public transport network is in central-south and central-east areas, huge traffic problems are produced including bad connectivity with health centres. In comparison with other areas of the city, especially with suburban municipalities, there is a $80 \%$ difference in network density. Our analysis found that the average time spent on foot to the nearest health centre is approximately 100 minutes. The reciprocal time to reach community (municipality) health centres is 21 minute. The average time for all citizens (patients) for reaching clinical centres is 42 minutes, and there is between 3,500 and 10,000 citizens per bus stop. The ideal travel time from bus stops for potential patients could be 20 min- utes (Figure 2). The GIS analysis shows that $30 \%$ of population in Belgrade has very high connectivity when travelling on foot, $14 \%$ high, $20 \%$ medium, $10 \%$ low, $12 \%$ very low, and $14 \%$ don't have any possibility to go on foot. The main problem is the connectivity between periphery municipalities such as Mladenovac, Lazarevac, Grocka, Surcin which don't have any or very low connectivity with central municipalities such as Palilula, Zvezdara, Vozdovac, Novi Beograd, Zemun, Cukarica. Better connectivity would at the same time be a possibility to connect with other ways of public transport, not only buses. After obtaining the gravity methods we found that central and west parts of the city have 2.5 times stronger gravity force compared to the south, as well as 3.5 times stronger gravity power compared to the northern parts of the city.

\section{Discussion}

Traffic mobility, geospatial dispersion of health centres and potential availability was studied and the results showed that some of the health facilities are not accessible by the public transport lines, especially not from the bus station. Generally, accessibility to health centres in the territory of Belgrade is moderate, although the highest density of health facilities is in the centre of the city, where the public transport network is the densest. Unfortunately, the traffic and transport system do not follow the constant growth of the city population, expansion of urban settlements, new business and economy activities.

A study in UK, which included calculations of the time needed for car travelling to certain public hospitals (surgery rooms), indicated that only $10 \%$ of residents needed less than $10 \mathrm{~min}$ to reach public transport services and that almost $13 \%$ of the population could not reach general medical services by daily buses (Lovett et al., 2002). For $5 \%$ of the population, the car journey to the nearest surgery was longer than $10 \mathrm{~min}$ and there was no suitable bus service on weekdays. While, for the city of Belgrade, the GIS analysis
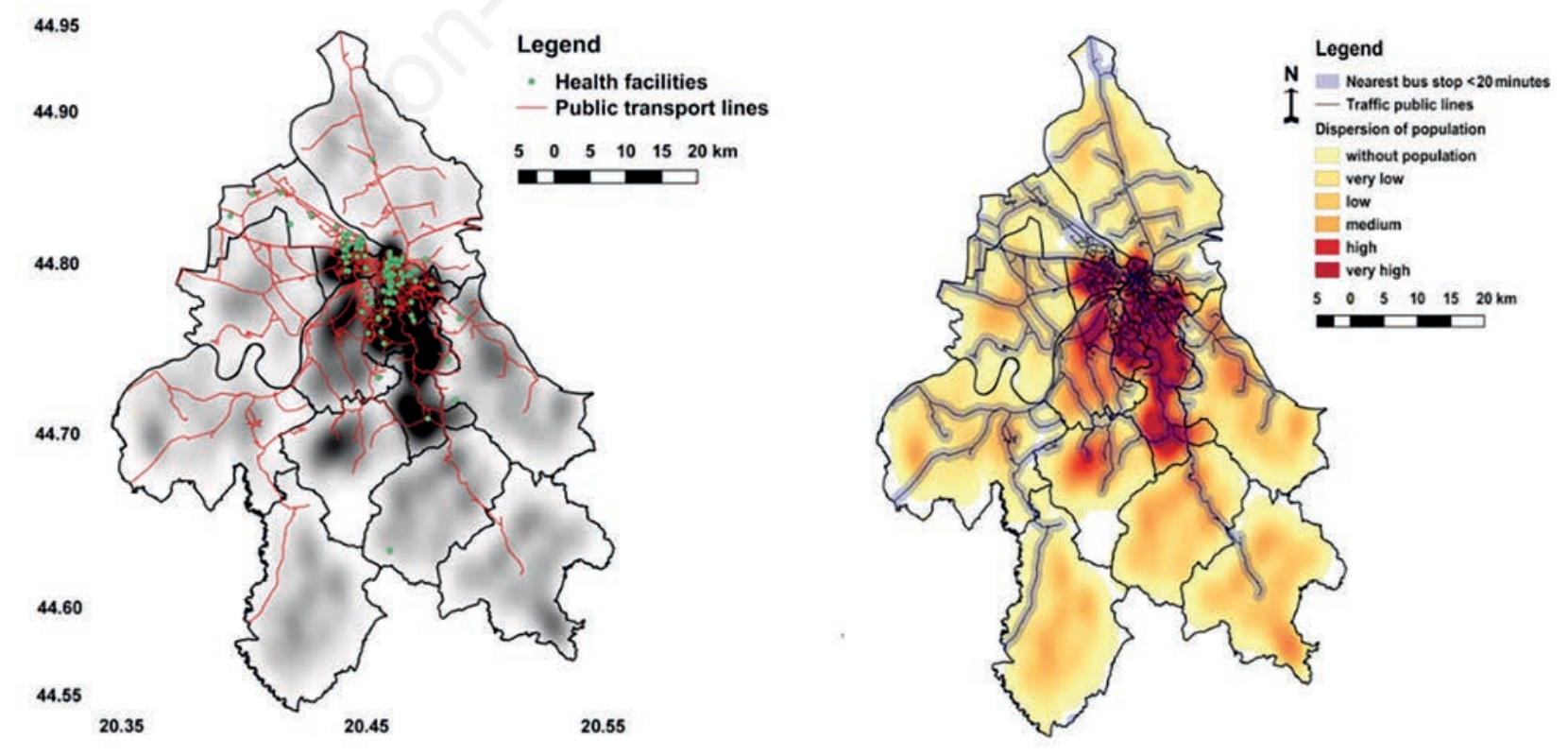

Figure 2. Population density map and traffic network map with buffer analysis. 


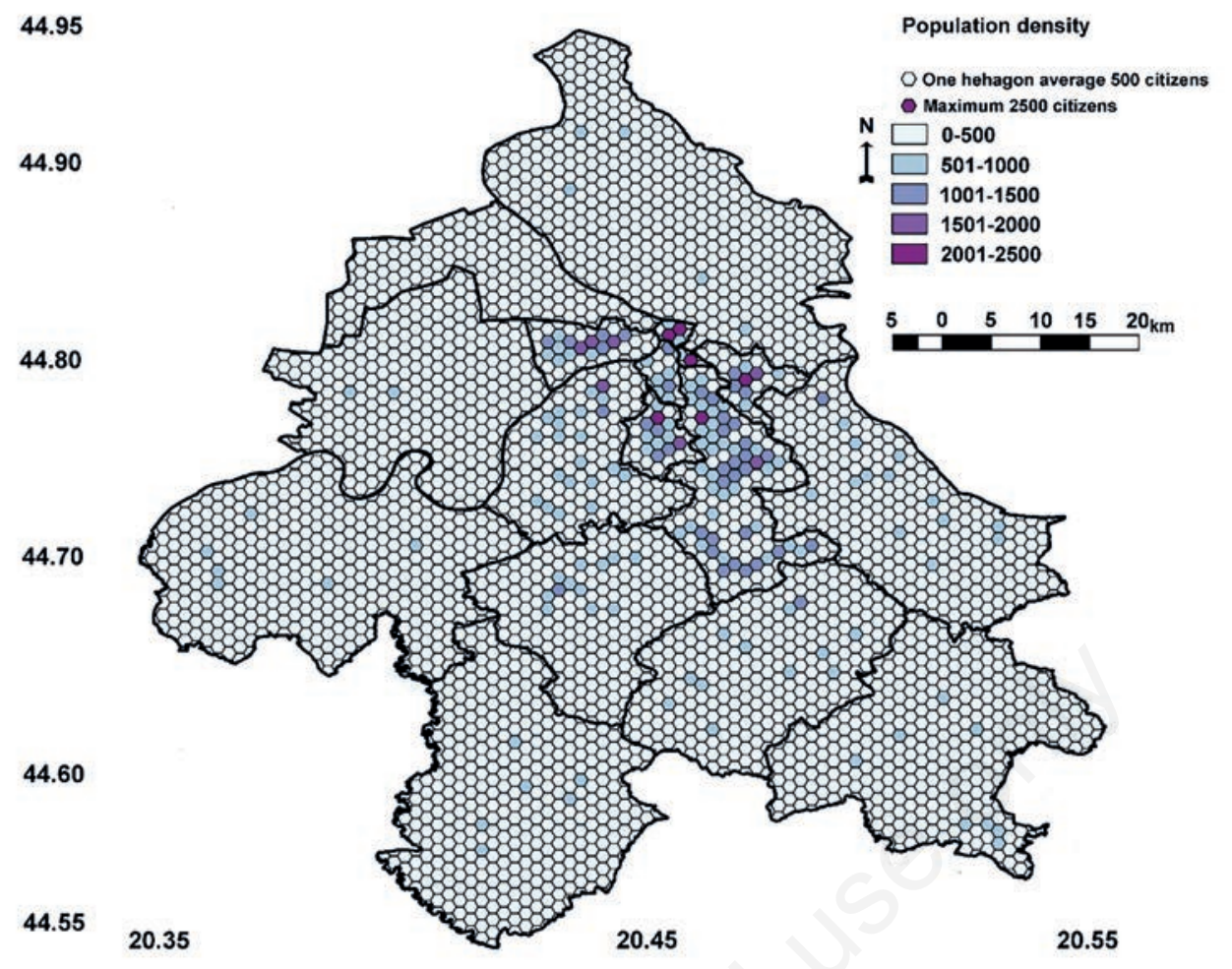

Figure 3. Hexagon map with estimated density of population in Belgrade.

shows that the average travel time from bus stops for potential patients is 20 minutes, but the average time spent to go on foot to the nearest health centre is approximately 100 minutes. Also, the results show that almost $36 \%$ of patients have low, very low or do not have any possibility for passage on foot to the nearest health centre. The average time of 42 minutes needed for all citizens (patients) to reach the nearest health centre shows that Belgrade has what can be called moderate connectivity.

The unplanned settlements, which appeared after the year 2000 , contribute to the transport problems in the city. In these parts of the city there are more than $40 \%$ of the total number of citizens. Also, there are almost 280,000 people, who have no connectivity with health care units at all, which very clearly indicates that periphery municipalities must adapt better. The Roma minority amounts to 100,000 people, who generally are without electricity and live in unplanned buildings under very miserable living conditions, which must be improved. This situation shows new public transport lines, especially buses, should be contemplated.

The average walking time to primary (community) health centres is currently too long and presents one emergency problem. Also, in the city, we have only $10 \%$ of other transport resources such as trams and trolleys, but these transport systems are only available in the central parts of the city. Another problem is the low connectivity between trams, trolleys and buses. The city railway is possible solution as it covers more than $35 \%$ of the potential network and is not exploited enough at the present time, and. Also, railway transport may be updated to include new light trains. Although the current subway with only three potential directions south-north, west-south-east and west-north-east already alleviates some road traffic, new subway lines could improve the situation further. With implementation of new night lines 30 minutes after midnight we can expect $30 \%$ higher number of passengers. Private and public health care centres may also include new traffic points, especially for bus. Also it is necessary to establish a new circular line with terminus of 30 minutes, which would be connecting all health centres in the city. For example, a study followed by a reform in Costa Rica satisfying results were obtained. The reform was conducted by targeting the least privileged population first and by including measures such as new community medical offices and basic teams for integrated health care to work with the people living there. All this indicates that in the territory of the city of Belgrade, there is not only a need, but also great expectations for a reform of the city transport as there are reasons to believe that it would establish a superior, general spatial plan of the city.

\section{Conclusions}

Faster emergency units would save more lives and people around the world have been gaining with regard to transport services, especially for medical services. In that case, accessibility to traffic lines has enormous importance. When the number of citizens increases, the city will have more problems which must be solved. Some of them are the effects of urban growth, since over $30 \%$ of the population currently inhabit the unplanned parts of the city. The creation of a municipal digital map which should be updated every hour can be very important for showing real transport problems; if also the spatial distribution of health centres could be added, transport to and from these facilities could be reduced. 


\section{References}

Anderson WP, 2012. Economic Geography. New York, NY: Routledge. pp 63-66.

Bartie P, Witten K, Pearce J, 2006. Neighbourhoods and health: a GIS approach to measuring community resource accessibility. Epidemiol Commun Health 60:373-82.

Bullen N, Moon G, Jones K, 1996. Defining localities for health planning: A GIS approach. Social Sci Med 42:801-16.

Cromley EK, McLafferty SL, 2011. 2nd ed. GIS and public health. New York, London: The Guilford Press.

De Jong T, Ritsema JR, 1999. Accessibility analysis and spatial competition effects in the context of GIS supported service location planning. Comput Environ Urban System 23:75-89.

De Jong T, Ritsema JR, Toppen F, 1991. GIS as a tool for locating service centers. In: Proceedings of the 2nd European GIS Conference, 1991. Utrecht: EGIS. pp 509-517.

Featherstone WE, 1994. An explanation of the Geocentric Datum of Australia and its effects upon future mapping. Cartography 2:1-12.

Ferreira MC, 2014. Geographical distribution of the association between El Niño South Oscillation and dengue fever in the Americas: a continental analysis using geographical information system-based techniques. Geospat Health 9:141-51.

Geertman SC, Bosveld W, 1990. A GIS based model for goals achievement analysis and design. Proceedings of the $1 \mathrm{st}$ European Conference on the Geographical Information Systems, 1990. Utrecht: EGIS. pp 356-365.

Handy SL, 1997. Measuring accessibility: an exploration of issues and alternatives Environ Planning 29:1175-94.

Higgs G, Gould M, 2001. Is there a role for GIS in the "new NHS'?. Health \& Place 7:247-59.

Higgs G, 2009. The role of GIS for health utilization studies: literature review. Health Serv Outcomes Res Methodol 9:84-99.

Howard AZ, Paul AR, Hensley S, 1997. Atmospheric effects in interferometric synthetic aperture radar surface deformation and topographic maps. J Geophys Res B4:7547-63.

Joyce K, 2009. "To me it's just another tool to help understand the evidence": Public health decision-makers' perceptions of the value of geographical information systems (GIS). Health \& Place 15:831-40.

Laohasiriwong W, Puttanapong N, Singsalasang A, 2018. Prevalence of hypertension in Thailand: Hotspot clustering detected by spatial analysis. Geospat Health 13:20-27.

Lovett A, Haynes R, Sunnenberg G, Gale S, 2002. Car travel time and accessibility by bus to general practitioner services: a study using patient registers and GIS. Social Sci Med 55:97111.

Martin C, Curtis B, Fraser C, Sharp B, 2002. The use of a GISbased malaria information system for malaria research and control in South Africa. Health \& Place 8:227-36.

Matijević D, 2005. Recent development of rural settlements in northern part of Belgrade periurban space. J Geogr Inst Jovan Cvijic SASA 54:75-86.

Matthew S, Bambang P, Cynthia SG, Ravi KS, 2006. Exploring the role of GIS during community health assessment problem solving: experiences of public health professionals. Int $\mathrm{J}$ Health Geogr 5:39.

McLafferty SL, 2003. GIS and health care. Annu Rev Public Health 24:25-42.

Mortarino M, Musella V, Costa V, Genchi C, Cringoli G, Rinaldi
L, 2008. GIS modeling for canine dirofilariosis risk assessment in central Italy. Geospatial Health 2:253-61.

Najafabadi AT, 2009. Application of GIS in Health Sciences. Shiraz E Med J 10:221-30.

Niedercorn JH, Bechdolt BV, 1969. An economic derivation of the "Gravity Law" of spatial interaction. J Region Sci 9:273-82.

Ogunyemi SA, Muibi KH, Eguaroje OE, Fabiyi O, Halilu AS, 2014. A geospatial approach to evaluation of accessibility to secondary educational institution in Ogun State, Nigeria. IOP Conf Series Earth Environ Sci 20:1-13.

Pouliou T, Elliott JS, Paez A, Newbold KB, 2014. Building obesity in Canada: understanding the individual- and neighbourhoodlevel determinants using a multi-level approach. Geospatial Health 9:45-55.

Ports S, Crucitti P, Latora V, 2006. The network analysis of urban streets: A dual approach. Phys A: Statist Mechan Appl 369:853-66.

Rodrigue JP, Comtois C, 2013. The geography of transport system, 3rd ed. New York, NY: Routledge. pp 24-43.

Rosero-Bixby LR, 2004. Spatial access to health care in Costa Rica and its equity: a GIS-based study. Social Sci Med 58:1271-84.

Simić A, 1974. Urbanization and cultural process in Yugoslavia anthropological quarterly 2:211-27.

Srivastava A, Napgal BN, Joshi PL, Paliwal JC, Dash AP, 2009. Identification of malaria hot spots for focused intervention in tribal state of India: a GIS based approach. Int J Health Geogr $8: 30$.

Statistical Office of the Republic of Serbia, 2015. Book of census data of 2015. Available from: http://webrzs.stat.gov.rs/

Valjarević A, Djekić T, Stevanović, V, Ivanović R, Jandziković B, 2018a. GIS Numerical and remote sensing analyses of forest changes in the Toplica region for the period of 1953-2013. Appl Geogr 92:131-9.

Valjarević A, Srećković-Batoćanin D, Valjarević D, Matović V, 2018b. A GIS-based method for analysis of a better utilization of thermal-mineral springs in the municipality of Kursumlija (Serbia). Renew Sustain Energy Rev 92:948-57.

Valjarević A, Srećković-Batoćanin D, Živković D, Perić M, 2015. GIS analysis of dissipation time of landscape in the Devil's city (Serbia). Acta Montanistica Slovaca 20:148-55.

Valjarević A, Vukoičić D, Valjarević, D, 2017. Evaluation of the tourist potential and natural attractivity of the Lukovska Spa. Tourism Manag Perspect 22:7-16.

Wilkinson PD, Tanser F, 1999. GIS/GPS to document increased access to community-based treatment for tuberculosis in Africa. Lancet 354:394-5.

Wu ST, Chen YS, 2016. Examining eco-environmental changes at major recreational sites in Kenting National Park in Taiwan by integrating SPOT satellite images and NDVI. Tourism Manag $57: 23-36$

Wei L, 2004. Using a GIS-based floating catchment method to assess areas with shortage of physicians. Health \& Place 10:111.

Xiong X, Luo L, 2017. Use of geographical information systems for delimiting health service areas in China. Geospat Health 12:96-105.

Zhan FB, Noon CE, 1998. Shortest path algorithms: an evaluation using real road networks. Transportat Sci 32:65-73. 